\title{
CHARACTERISTICS OF ARCTIC SEA ICE FROM REMOTE-SENSING DATA AND THEIR RELATIONSHIP TO ATMOSPHERIC PROCESSES
}

\author{
by
}

Roger G. Barry, Martin W. Miles, Richard C. Cianflone, G. Scharfen, and Russell C. Schnell

(Cooperative Institute for Research in Environmental Sciences (CIRES), University of Colorado, Boulder, CO 80309-0449, U.S.A.)

\section{ABSTRACT}

New data on leads and surface-melt phenomena in the Arctic, based on mapping of DMSP visible images, are presented. Lead orientations in the Beaufort Sea are broadly correlated with geostrophic wind direction and show similar synoptic scale patterns. Preliminary results of airborne $1.06 \mu \mathrm{m}$ lidar transects over Baffin Bay demonstrate its great potential for high-resolution mapping of open-water areas and, in winter/spring, their ice-crystal plumes. Some of these sub-visible plumes are observed to penetrate the Arctic inversion. Snow-melt maps for the entire Arctic prepared for four summer seasons have been used to derive surface-albedo data. From these data the variability of the surface-energy balance is estimated to be equivalent to $0.6 \mathrm{~m}$ of ice melt.

\section{INTRODUCTION}

Fuller understanding of the response of sea ice to seasonal and shorter-term atmospheric forcing through data analysis and numerical modelling is currently hindered by the limited data on ice characteristics and on contemporaneous atmospheric and oceanic conditions. The only ice variable for which substantial records exist is ice extent (Barry, 1986). Information is also needed on ice concentration, ice thickness, and the snow cover on the ice, as well as ice velocity. Our work seeks to provide data on several related parameters, on a variety of space- and time-scales, using a combination of remote-sensing measurements. New sources of data on Arctic leads, polynyi, and surface-melt phenomena derived from DMSP visible satellite images and from airborne lidar measurements are reported. The associated atmospheric conditions are examined using measurements from the Arctic drifting-buoy network (Thorndike and Colony, 1980; Colony and Muñoz, 1985).

\section{LARGE-SCALE CHARACTERISTICS OF OPEN-WATER} AREAS IN THE ARCTIC

\section{Mapping from satellite images \\ The spatial and temporal occurrence of open-water areas (leads and polynyi) are of major significance for the ocean-atmosphere exchange of heat and moisture, especially in winter (Maykut, 1986). Leads form as a result of tensile failure in the ice, in response to the shear stresses induced by the differential motions of both the air and water. Ideally, leads "form in a band of uniform width, running at right angles to the direction of the major principal stress in the ice sheet" (Mellor, 1986, p. 264). Little information exists about the distribution of leads and polynyi on a basin-wide scale. We aim to fill this gap by mapping open- water areas from satellite imagery.}

The Defense Meteorological Satellite Program (DMSP) polar-orbiting satellites provide direct read-out images with $0.6 \mathrm{~km}$ resolution, covering much of the Canada Basin sector of the Arctic Ocean; these are available in the National Snow and Ice Data Center, Boulder, Colorado. Initially,
DMSP visible $(0.4-1.1 \mu \mathrm{m})$ and infra-red $(8-13 \mu \mathrm{m})$ images for the sector $70^{\circ}-85^{\circ} \mathrm{N}, 160^{\circ} \mathrm{E}-130^{\circ} \mathrm{W}$ were compared with Landsat images from the same date. Landsat images have a nominal resolution of $80-100 \mathrm{~m}$, but enable detection of much smaller high-contrast linear features. It was found that under cloud-free conditions leads $3300 \pm 50 \mathrm{~m}$ can be detected on the DMSP images, which, unlike Landsat, are available on a daily basis. Leads of this size represent approximately $1-2 \%$ of the lead-frequency distribution, as estimated from submarine sonar data in the Canada Basin (McLaren, in press), but they account for about 20\% of the totai open-water/young-ice $(0-30 \mathrm{~cm}$ thick) area and are of major significance for ocean-atmosphere energy fluxes and in terms of large-scale ice dynamics. The time intervals

\section{a}

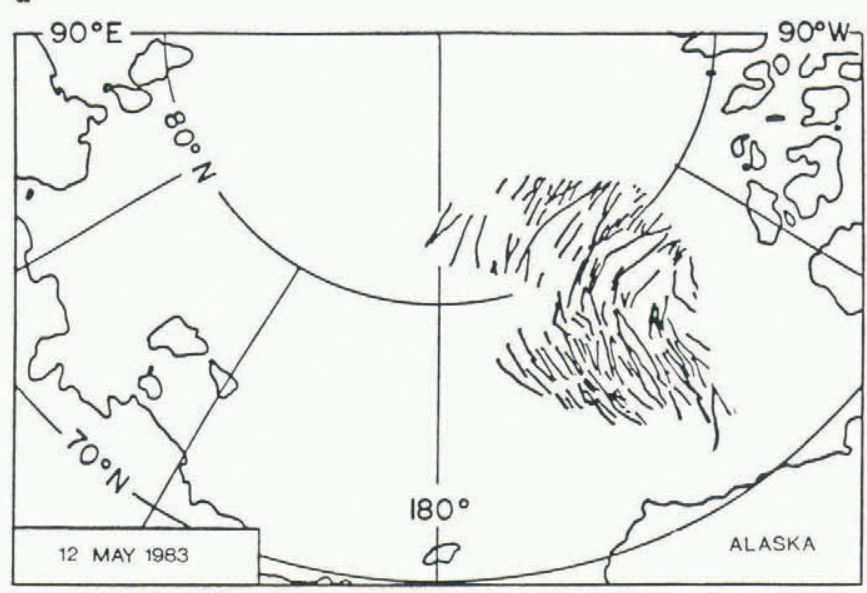

b

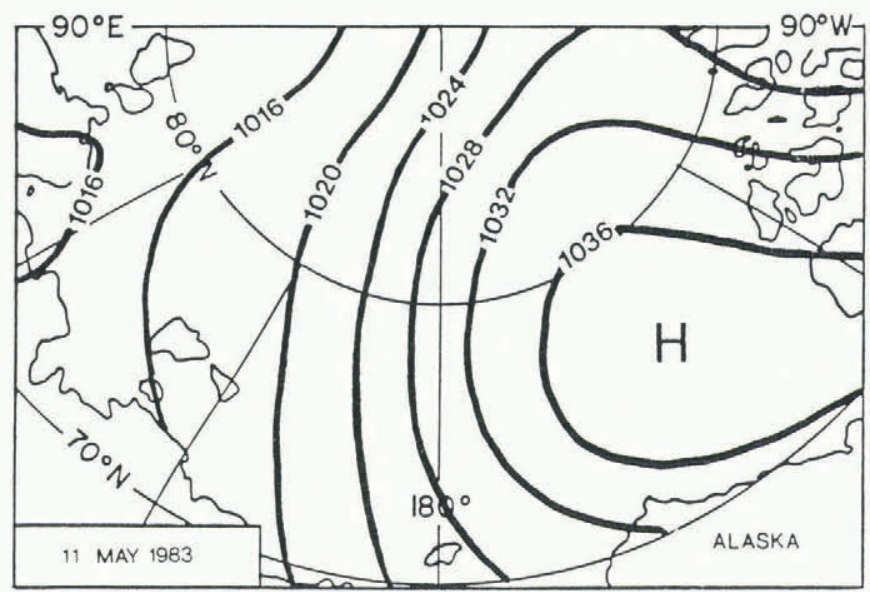

Fig. 1. (a) Distribution of leads $\geqslant 300 \mathrm{~m}$ in the Beaufort Sea identified from DMSP $(0.6 \mathrm{~km}$ resolution) visible images for 12 May 1983. (b) Mean sea-level pressure (mbar) for 11 May 1983. 

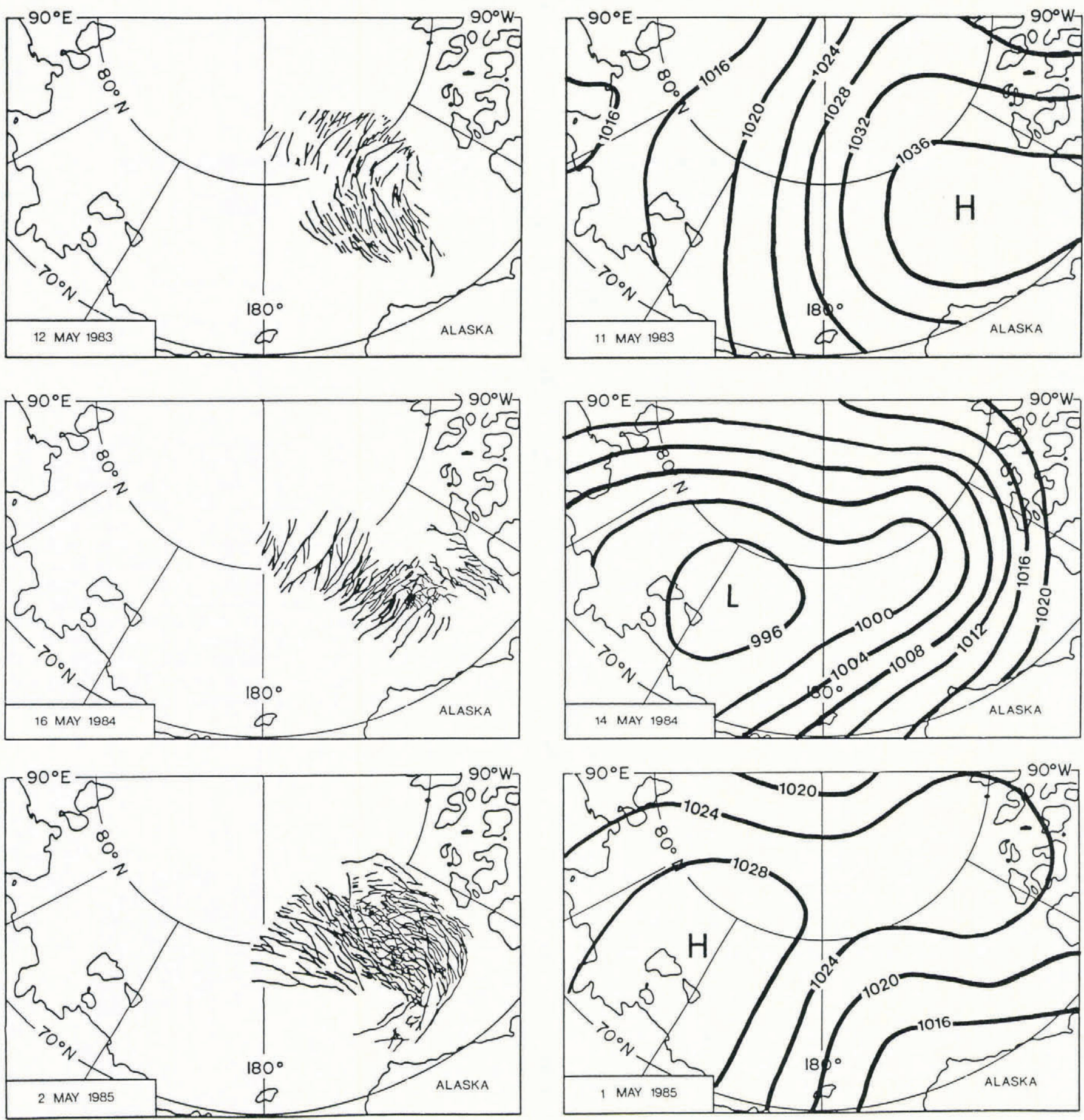

Fig. 2. Lead patterns and corresponding mean sea-level pressure (mbar) patterns in the Beaufort Sea in May of three successive years: (a) 1983; (b) 1984; (c) 1985.

when leads can be mapped from visible images of the Arctic Ocean are generally April-June/July and SeptemberOctober. Darkness and thick or persistent clouds exclude analysis of the other months, except from infra-red images in the winter when cloud amounts are generally low.

Lead occurrence and orientation are determined from DMSP images (for 1980 and 1982-85) by using a $1^{\circ}$ latitude by $5^{\circ}$ longitude grid overlay. The lead orientation in each grid cell containing observable leads is calculated trigonometrically as a vector showing the preferred direction and the strength of this preference, following Curray (1956). The location of leads $\geqslant 300 \mathrm{~m}$ across is shown in Figure 1 for 12 May 1983, during the season of minimum ice velocity (McLaren and others, 1987). It illustrates the general tendency for leads to be arranged roughly parallel to the geostrophic wind direction, as shown by the corresponding mean sea-level pressure map (Fig. 2). The lead patterns, therefore, show similar space scales to atmospheric synoptic systems. Their space-time characteris- tics are now discussed more fully in relation to surface geostrophic winds.

\section{Relationship to the wind field}

To analyze the large-scale relationships between the wind field and the lead orientations more systematically, geostrophic winds have been derived from the daily gridded pressure data provided by the Arctic Ocean Buoy Program (Thorndike and Colony, 1980). The wind fields are referenced to the $1^{\circ} \times 5^{\circ}$ grid and correlated with the lead-orientation values in each grid box using wind values for each of the $2 \mathrm{~d}$ preceding the date of the lead observation. Wind directions and lead orientations are both recorded in $15^{\circ}$ intervals. In this manner, each grid cell has a pair of angular values: (1) lead orientation $(\phi)$ and (2) wind direction $(\theta)$, and the difference $\delta=\phi-\theta$.

There is no generally agreed upon measure of directional/vector correlation; several different correlation statistics have been recently proposed, both non-parametric 
and parametric (Klink, unpublished). For this research, an appropriate correlation statistic was selected for its ability to include: (1) a bounded range, (2) rotational dependencies, and (3) ease of interpretation, as suggested by Klink (unpublished). For this research, the fact that the lead "direction" has two values, $\phi$ and $\phi+180^{\circ}$, is also important.

The correlation statistic used is essentially that prescribed by Batschelet (1981), where $r_{\mathrm{B}}$ is the correlation coefficient:

$$
\begin{gathered}
r_{\mathrm{B}}=N^{-1}\left\{\left[\sum_{n=1}^{N} \cos \delta i\right]^{2}+\left[\sum_{i=1}^{N} \sin \delta i\right]^{2}\right\}^{\frac{1}{2}}, \\
0 \leqslant r_{\mathrm{B}} \leqslant 1 .
\end{gathered}
$$

A large $r_{\mathrm{B}}$ value indicates that $\phi$ is strongly dependent on $\theta$ whereas, if $r_{\mathrm{B}}$ approaches zero, the two variables are uncorrelated. This statistic can be modified to give the direction of the rotation (angular co-variation) and direction of a mean resultant correlation vector (Klink and Willmott, 1985). These correlation procedures provide an indicator of the variability of lead patterns which may be attributable to atmospheric forcings. For the case illustrated in Figure 1, the correlation coefficients (averaged over 62 grid points) are 0.80 (day -2 ), 0.91 (day -1 ), and 0.90 (day 0 ). Of 15 cases for which $3 \mathrm{~d}$ statistics could be obtained, three show a high correlation $\left(r_{\mathrm{B}}>0.82\right)$ between lead orientation and wind direction, ten are moderately correlated $\left(r_{\mathrm{B}}=\right.$ $0.57-0.82)$, and two are weakly correlated $\left(r_{\mathrm{B}}<0.57\right)$. These classes correspond to $>66,33-66$, and $<33 \%$ of the variance explained. The results are summarized in Table I.

There are several parameters of interest in the analysis.
The response time of the orientation of major lead patterns to changes in the wind field can be determined. It is evident from several weekly series of images that lead orientations may change noticeably within $24 \mathrm{~h}$ of changes in the wind field; but in other cases they exhibit substantial persistence of orientation. For example, during March-April 1980 , the lead pattern remained essentially unchanged for several weeks. In this case, ice concentration was high, and ice velocities were low despite the presence of fairly persistent anti-cyclones. As a result of synoptic variability in the atmosphere, there is also considerable inter-annual variability in lead orientation. Figure 2 illustrates this for dates in early May from three different years. An initial objective of the study was to determine whether there might be sufficient regularity in lead orientation at given seasons such that statistics of lead widths and keel spacings, derived from submarine sonar measurements of under-ice topography, could be interpreted more quantitatively. At present, it is generally unknown whether submarine transects are perpendicular to or sub-parallel to ice openings, for example. The results of this work indicate substantial temporal variability in lead patterns. Consequently, it would be necessary to have almost synchronous aircraft or satellite imagery for a given submarine transect in order to compare it with submarine sonar measurements of leads and ridge keels. Nevertheless, our results suggest that a first approximation of the field of major fracture orientations could be "modelled" given appropriate geostrophic wind data.

The seasonal variation in the observed relationships of leads and wind fields is also of interest. In general, the winter months are expected to be less likely to show a strong relationship between lead patterns and wind fields, as a result of the compact sea-ice conditions in winter. Motion in the Beaufort Gyre is low in April, for example, despite

TABLE I. CORRELATION OF GEOSTROPHIC WIND AND LEAD ORIENTATION FROM CASE STUDIES. CORRELATION COEFFICIENT $\left(r_{B}\right)$ AND ANGLE OF ROTATION $\left(\alpha_{B}\right)$ ARE SHOWN FOR WINDS DURING THE $3 \mathrm{~d}$ PRECEDING THE LEAD OBSERVATION. (MEAN VALUES ARE FROM $Z$-SCORE CONVERSION.) $\alpha_{\mathrm{B}}>0$ INDICATES THAT THE LEAD IS ROTATED CLOCKWISE FROM THE WIND DIRECTION

Winter/Spring

Date

18 Mar 1980

14 Apr 1980

1 Feb 1983

12 May 1983

22 Nov 1983

23 Jan 1984

15 May 1984

12 Dec 1985

Mean

$2 \mathrm{~d}$ before

$1 \mathrm{~d}$ before

Same day

Mean

correlation

$r_{\mathrm{B} 2} \quad \alpha_{\mathrm{B} 2}$

$r_{\mathrm{B} 1}$

$\alpha_{\mathrm{B} 1}$

$r_{\mathrm{B} 0}$

$\alpha_{\mathrm{B} 0}$

$\bar{r}_{\mathrm{B}}$
0.53

0.81

0.56

0.80

0.70

0.83

0.81

0.75

0.73

+64
-69
+6
-30
+16
-15
+35
+15
+3

0.72

0.44

0.64

0.91

0.88

0.78

0.65

0.71

0.75

\section{$+84$}

$-74$

$+6$

$-22$

$+3$

$-57$

-69
+5

$+5$

$+2$
0.11

0.10

0.74

0.90

0.88

0.88

0.52

0.48
$0.71-34$
-35
-69

$+4$

$-16$

$+26$

$-64$

$-72$

$-47$
0.47

0.68

0.65

0.88

0.84

0.84

0.68

0.66

0.73

Summer/Fall

Date

28 Sep 1983

8 June 1984

13 Aug 1984

30 Sep 1984

26 Oct 1984

18 Jan 1985

18 Oct 1985

Pressure

L
H
H
H
H
H
L
H

Mean

$r_{\mathrm{B} 2}$

$\alpha_{B 2}$

$r_{\mathrm{B} 1}$

$\alpha_{B 1}$

$r_{\mathrm{B} 0}$

$\alpha_{B 0}$

$\bar{r}_{\mathrm{B}}$

Pressure

regime

$-27$

$0.71+12$
L

Weak

$\mathrm{H}$

$\mathrm{H}$

$\mathrm{H}$

$\mathrm{H}$

L 
the fact that the intensity of the Arctic anti-cyclone reaches a maximum in this month (McLaren and others, 1987). However, Table I shows little or no seasonal variation in the directional correlation coefficients. There are also no consistent patterns in the timing of the maximum correlation between wind direction and lead orientation over the $3 \mathrm{~d}$ and no apparent seasonal differences. The angles of rotation of the leads from the wind direction (averaged over the array) are also highly variable (Table I). In winter-spring, the mean angular values are near zero during days 1 and 2 prior to the date of the lead map and $-34^{\circ}$ (counter-clockwise rotation of the lead from the geostrophic wind) on the same day. In summer-fall, leads are rotated $12^{\circ}$ clockwise from the wind and are more strongly rotated $2 \mathrm{~d}$ prior. However, large samples are needed to produce an adequate characterization of the relationships.

Thorndike and Colony (1982) have reported that over $70 \%$ of the variance of ice velocity in the central Arctic is explained by the geostrophic wind. The results thus far indicate that lead patterns are also moderately correlated with the geostrophic wind, although there are many complicating considerations. The frequency, intensity, and persistence of cyclonic and anti-cyclonic disturbances are additional factors contributing to lead characteristics, as are the antecedent lead patterns and other ice characteristics (for example, ridges, grounded ice, etc.). Where the observed relationship between leads and winds is weak, the over-riding factor is the continuing state of the antecedent lead conditions due to the near absence of ice motion over all or part of the study area.

\section{AIRBORNE LIDAR OBSERVATIONS OF OPEN-WATER AREAS}

A new source of high-resolution information on the sizes of leads and other open-water areas is provided by airborne lidar measurements. Near-infra-red $(1.06 \mu \mathrm{m})$ wavelength lidar is highly sensitive to particulates due to the large ratio of particulate/molecular back-scatter. This enables open-water areas to be detected in the winter half-year by their plumes of moisture and ice crystals. A lidar instrument was flown in the eastern Canadian Arctic in January 1984 and March-April 1986 in conjunction with the Arctic Gas and Aerosol Sampling Program (AGASP). The lidar surface resolution ("footprint") is on the order of $1 \mathrm{~m}$, but at a typical air speed there is a pulse about every $30 \mathrm{~m}$, yielding an "effective" resolution of $30 \mathrm{~m}$. However, our initial work has been performed by manual analysis of the facsimile plots of the same data (Morley, 1987), which permit only more generalized mapping of features $\geqslant 200 \mathrm{~m}$. These records have been analyzed and compared with suitable cloud-free visible and infra-red DMSP satellite images and with operational sea-ice charts and weather data for corresponding dates.

The results of a preliminary statistical analysis of the available analog data for northern Baffin Bay for a total track length of $1300 \mathrm{~km}$ indicate a modal value for width of open-water areas of $c .200 \mathrm{~m}$, the limit of discrimination of the facsimile plots, and a median width of approximately $1 \mathrm{~km}$ (Fig. 3). These results may be compared with those

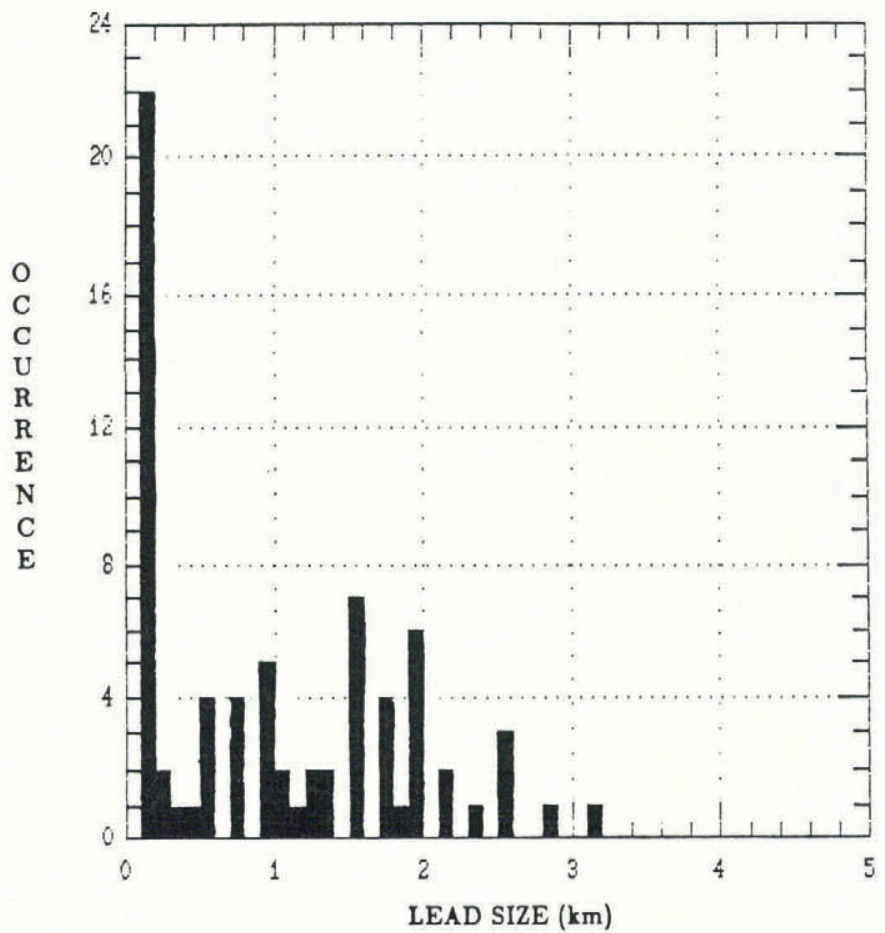

Fig. 3. Frequency histogram of fracture sizes in northern Baffin Bay based on aircraft lidar data $(1.06 \mu \mathrm{m})$ for three flights 2-9 April 1986. The lower cut-off is due to the resolution of the facsimile plots. Data are grouped in $100 \mathrm{~m}$ size classes.

obtained in previous research in the study region (Steffen, 1987). His studies for $1800 \mathrm{~km}$ of flight line in the North Water area of Baffin Bay indicate that $90 \%$ of the ice fractures (leads and refrozen leads) are less than $600 \mathrm{~m}$ wide, and fractures greater than $1.2 \mathrm{~km}$ are very rare. Steffen found a log-linear decrease in frequency of larger leads, whereas Figure 3 shows a higher frequency of wider fractures. Comparison of the flight tracks with a visible AVHRR image for 4 April 1986 confirmed that major leads were present in Baffin Bay and permitted the coastal polynyi to be excluded from the analysis. The discrepancy may reflect seasonal differences, since regional differences between the North Water area and the main part of Baffin Bay seem unlikely in view of Steffen's inter-comparison of encounters with fractures versus fracture width in Baffin Bay, North Water, M'Clure Strait, and Lancaster Sound (Steffen, 1987, fig. 4). Our future analyses will make use of the digital lidar data collected in the Arctic in 1984, yielding higher resolution and permitting more precise statistics to be obtained.

In addition to compilation of statistics on open-water areas, an estimation from the lidar data of water and heat fluxes from openings in the ice is of considerable interest for the assessment of surface and atmospheric energy budgets and maintenance of the Arctic inversion. Figure 4

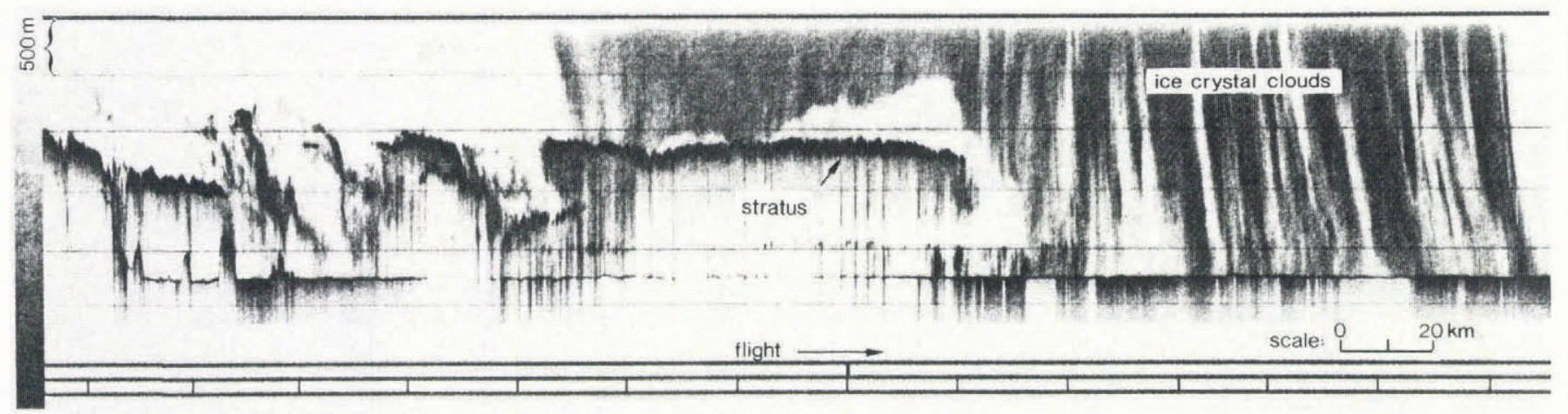

Fig. 4. Analog record from airborne lidar over Baffin Bay, 18 April 1986. The horizontal lines are at $0.5 \mathrm{~km}$ intervals above the surface; the scale below the surface is arbitrary. Stratus and ice-crystal plumes are evident; leads and polynyi are identified by the clear areas below the surface. 
illustrates a plot of lidar data over Baffin Bay on 18 April 1986. The lidar penetrates thin ice and accordingly refrozen areas as well as openings are identifiable, except below stratus cloud. The depth of penetration of the lidar is not at present known; however, the returns shown from below the surface on Figure 4 should be regarded as having an arbitrary vertical scale. Microphysical measurements by the aircraft showed that the plumes are composed of ice crystals, whereas the stratus is composed of water droplets which completely attenuate the lidar signal. Ice-crystal plumes extending beyond $2.5 \mathrm{~km}$ altitude are apparent. In some cases, the plume on an image may be associated with leads or small polynyi not directly below the flight track. Therefore, correlation of these records with satellite images requires a synchronous pass and locational precision of the flight track.

Figure 4 and other examples show that ice-crystal plumes may penetrate the Arctic inversion, transporting substantial amounts of heat and moisture into the lower troposphere, up to at least $4 \mathrm{~km}$ altitude. This is contrary to the prevailing view that most of the heat remains within the stable boundary layer or is returned to the surface down-wind of leads. Field measurements, taken during the AIDJEX Lead Experiment (Andreas and others, 1979), show that the turbulent-heat fluxes from leads can exceed $400 \mathrm{~W} \mathrm{~m}^{-2}$ for sensible heat and $130 \mathrm{~W} \mathrm{~m}^{-2}$ for latent heat, which is released as the water vapor rapidly forms ice crystals in the cold air. These heat fluxes provide the necessary buoyancy for the upward motion of plumes.

Following compilation of sufficient statistics on lead occurrence from the available lidar data and future flight programs, it should be feasible to develop improved estimates of the contribution of turbulent-heat fluxes to energy budgets in the Arctic on a regional scale during winter and spring.

\section{SNOW MELT ON ARCTIC SEA ICE}

The temporal and spatial progression of the melting of snow cover on the sea ice has been mapped manually from DMSP visible images for the entire Arctic Ocean at $3 \mathrm{~d}$ intervals for four summer seasons based on tonal contrasts and textural patterns (Scharfen and others, 1987). The methods used to carry out the mapping for four ice-surface classes and to convert the information into estimates of surface albedo are described in the paper cited.

Examination of the results of each of the 4 years $(1977,1979,1984$, and 1985) shows considerable interannual and spatial variability in the timing of snow melt and the subsequent ponding and drainage of the ice between early May and mid-August. This is illustrated by the spatial progression of melt in 1977 and 1979, the years of greatest difference in overall timing so far examined (Scharfen and others, 1987). In both 1977 and 1979, the monthly pressure fields for May and June show mean high pressure over the Arctic Basin. However, June 1977 had a greater frequency of days with anti-cyclone centres and, as a result, the central Arctic experienced cloud-free conditions in about $20 \%$ of days in 1977 compared with only $8 \%$ in June 1979 (Robinson and others, 1985). This would greatly augment the solar radiation reaching the surface. In each year studied, the melt of snow cover begins in the Barents and Kara Seas and more or less simultaneously in the southern Beaufort and Chukchi Seas, progresses along the Arctic coast of Asia, and then extends towards the American side of the North Pole.

Estimated surface albedos over the entire Arctic Basin are most variable in June with, for example, a monthly average of only 0.58 in 1977 compared with 0.66 in 1979 (Table II). In three out of five sub-regions, the difference in June albedo between these 2 years was $\geqslant 0.1$. The

TABLE II. INCOMING SOLAR RADIATION (AFTER MARSHUNOVA, 1966), MAXIMUM AND MINIMUM SURFACE ALBEDOS OF FOUR SEASONS (FROM SCHARFEN AND OTHERS, 1987), AND CORRESPONDING VALUES OF ABSORBED SOLAR RADIATION $\left(\mathrm{MJ} / \mathrm{m}^{2}\right)$

\begin{tabular}{|c|c|c|c|c|c|c|c|c|}
\hline & & A & M & $\mathbf{J}$ & $\mathrm{J}$ & A & $\mathrm{S}$ & $\mathrm{O}$ \\
\hline & \multicolumn{8}{|c|}{ Central Arctic } \\
\hline \multirow[t]{2}{*}{ Incoming solar radiation } & & 339 & 737 & 804 & 565 & 347 & 92 & \\
\hline & $\min$ & - & 0.78 & 0.66 & 0.52 & 0.50 & - & - \\
\hline \multirow[t]{2}{*}{ Albedo } & $\max$ & - & 0.79 & 0.76 & 0.59 & 0.54 & - & - \\
\hline & $\max$ & - & 162 & 273 & 271 & 174 & - & - \\
\hline \multirow[t]{2}{*}{ Absorbed solar radiation } & $\min$ & - & 154 & 193 & 231 & 159 & - & - \\
\hline & \multicolumn{8}{|c|}{ Beaufort/Chukchi Sea } \\
\hline \multirow{2}{*}{ Incoming solar radiation } & & 431 & 615 & 645 & 447 & 314 & 197 & 67 \\
\hline & $\min$ & - & 0.74 & 0.58 & 0.41 & 0.33 & - & - \\
\hline \multirow{2}{*}{ Albedo } & $\max$ & - & 0.77 & 0.65 & 0.47 & 0.42 & - & - \\
\hline & $\max$ & - & 160 & 270 & 281 & 210 & - & - \\
\hline \multirow[t]{2}{*}{ Absorbed solar radiation } & $\min$ & - & 141 & 226 & 253 & 182 & - & - \\
\hline & \multicolumn{8}{|c|}{ E. Siberian/Laptev Sea } \\
\hline \multirow{2}{*}{ Incoming solar radiation } & & 429 & 670 & 649 & 502 & 345 & 140 & 37 \\
\hline & $\min$ & - & 0.73 & 0.55 & 0.40 & 0.25 & - & - \\
\hline \multirow[t]{2}{*}{ Albedo } & $\max$ & - & 0.79 & 0.67 & 0.49 & 0.47 & - & - \\
\hline & $\max$ & - & 181 & 292 & 301 & 259 & - & - \\
\hline \multirow[t]{2}{*}{ Absorbed solar radiation } & $\min$ & - & 141 & 214 & 256 & 183 & - & - \\
\hline & \multicolumn{8}{|c|}{ Kara/Barents Sea } \\
\hline \multirow[t]{2}{*}{ Incoming solar radiation } & & 387 & 565 & 601 & 486 & 283 & 126 & 31 \\
\hline & $\min$ & - & 0.63 & 0.48 & 0.27 & 0.15 & - & - \\
\hline \multirow[t]{2}{*}{ Albedo } & $\max$ & - & 0.77 & 0.58 & 0.32 & 0.22 & - & - \\
\hline & $\max$ & - & 209 & 312 & 354 & 240 & - & - \\
\hline \multirow[t]{2}{*}{ Absorbed solar radiation } & $\min$ & - & 130 & 252 & 330 & 220 & - & - \\
\hline & \multicolumn{8}{|c|}{ North-west North Atlantic } \\
\hline \multirow{2}{*}{ Incoming solar radiation* } & & 349 & 737 & 804 & 565 & 347 & 105 & - \\
\hline & $\min$ & - & 0.70 & 0.59 & 0.45 & 0.43 & - & - \\
\hline \multirow[t]{2}{*}{ Albedo } & $\max$ & - & 0.74 & 0.62 & 0.50 & 0.44 & - & - \\
\hline & $\max$ & - & 221 & 329 & 310 & 198 & - & - \\
\hline Absorbed solar radiation & $\min$ & - & 191 & 305 & 282 & 194 & - & - \\
\hline
\end{tabular}

* North-west North Atlantic: solar radiation values averaged for $85^{\circ} \mathrm{N} / 60^{\circ} \mathrm{E}$ and $85^{\circ} \mathrm{N} / 0^{\circ} \mathrm{E}$. 


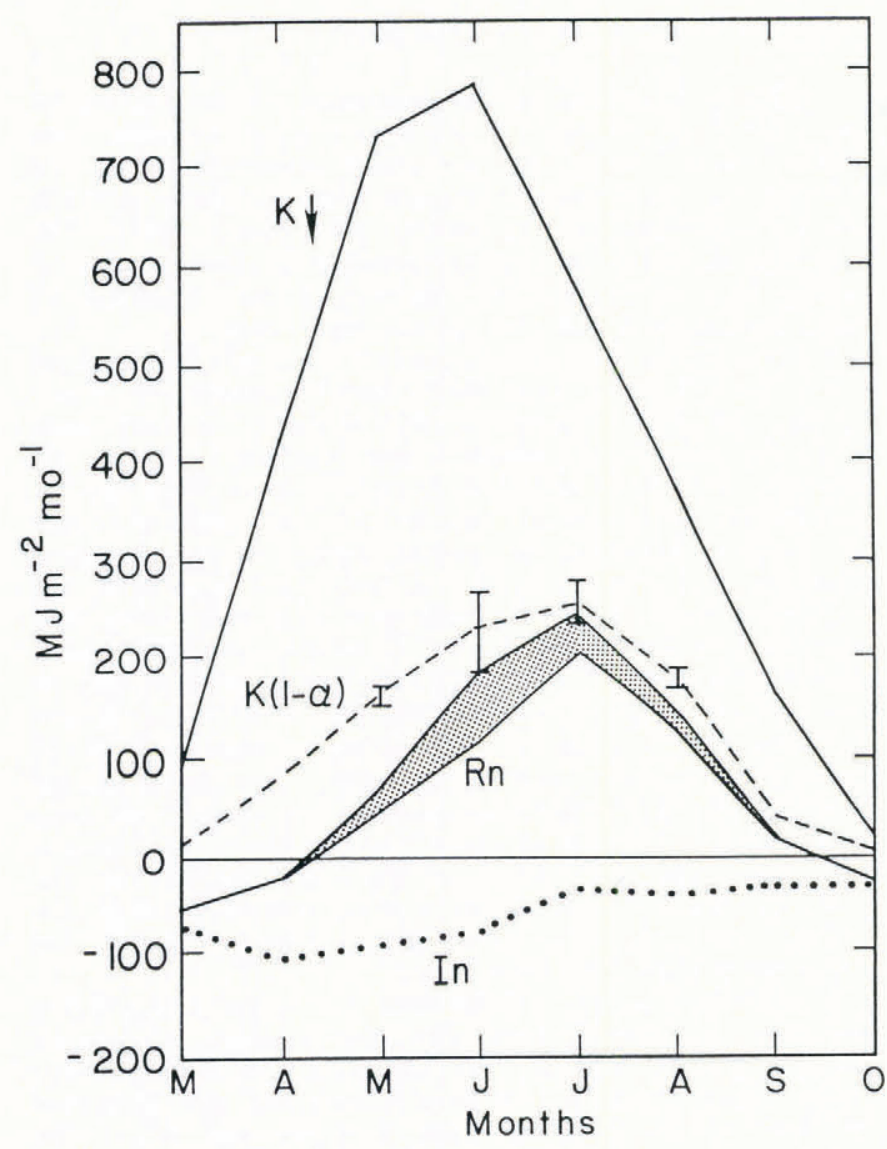

Fig. 5. Surface-energy budget components for the central Arctic (based on Maykut, 1986). $K \downarrow=$ incoming solar radiation, $K(1-\alpha)=$ absorbed solar radiation, $I n=$ net infra-red radiation, and $R n=$ net radiation. The bars denote ranges corresponding to the maximum and minimum albedos observed over 4 years.

Eurasian marginal seas exhibit even larger variability in May and June. The potential significance of these differences is indicated by Figure 5 showing the mean surface-energy budget for the central Arctic and the effects of the calculated range of albedo values. Figure 5 also shows how the presence of snow cover limits the fraction of incoming solar radiation that is absorbed at the surface and causes a 1 month lag in the peak of absorbed radiation behind that of the incoming radiation. The calculated seasonal difference in surface net radiation between maximum and minimum albedo values for the central Arctic amounts to approximately $160 \mathrm{MJ} \mathrm{m}^{-2}$. Hypothetically, this is sufficient for melting $0.66 \mathrm{~m}$ of saline ice. The percentage increase in absorbed energy between maximum and minimum values of surface albedo amounts to $19 \%$ for the central Arctic, but reaches $30 \%$ over the East SiberianLaptev Seas (Table II). This implies that ice conditions in this sector in late summer can be expected to undergo large inter-annual variations.

\section{DISCUSSION}

Sea-ice models aim to describe ice drift and the build-up and decay of ice thickness (Hibler, 1985). Typically, simulations of the variations of ice-edge location and ice compactness are performed. For verification of climate models incorporating an interactive ocean with a sea-ice cover, data are needed on both mechanical and thermodynamic processes in the ice (World Climate Research Programme, 1987). The essential ice variables are: concentration (and edge position) determined every $3 \mathrm{~d}$ on a $30 \mathrm{~km}$ grid, ice thickness, and daily ice velocity on a $500 \mathrm{~km}$ grid. Ice concentration can now be determined from multi-frequency passive microwave data. However, there is still need for refinement and testing of the algorithms, especially in the marginal ice zone where weather systems may mask the ice signature and during the summer when melt phenomena complicate the interpretation (Maslanik and Barry, 1989). The attainable accuracies, unless supplemented by other data, are c. $10 \%$ for first-year ice and $30 \%$ for multi-year ice. Ice velocity can currently be determined from the Arctic buoys and in the 1990s this information will be greatly augmented by synthetic aperture radar (SAR) data to be provided by the European and Japanese Earth resources satellites. Data on ice draft are collected by upward-looking sonar systems in submarines, but only limited amounts of such data have so far been released and analyzed (Wadhams and Horne, 1980; Bourke and Garrett, 1987; McLaren, in press). The spatial distribution of ice thickness, even for seasonal averages, cannot yet be reliably stated. Such statistics are important in terms of both the model dynamics and for thermodynamic calculations of heat exchange.

The products currently being prepared, as described above, provide a basis for interim model testing. For example, Ross and Walsh (1987) have simulated snow-melt progression. Starting from late spring snow-depth estimates, based on a climatological assessment using observations made at coastal and island stations for 1977 and 1979, and using actual climatic forcings for these years, they simulated the decay of the snow cover for the Arctic Ocean sectors defined by Scharfen and others (1987). They were able to reproduce both inter-annual contrast between these two seasons, illustrated earlier, and spatial differences on the rate of decay of the snow cover. Extension of the snow-melt mapping to another six seasons is in progress, in order to provide a more adequate sample of inter-annual variability and to permit verification of simulated conditions for additional years.

We suggest that the statistics on the spatial occurrence of leads and other openings in relation to various synoptic forcings will also be useful for examining the dynamic characteristics of sea-ice models. The rapidity, or otherwise, of change in patterns of leads in response to wind-velocity changes for varying conditions of ice compactness provides information on the appropriate rheology for different regions or stages of the seasonal cycle.

The climatic implications of the ice characteristics (lead fraction and surface albedo) in terms of ocean and iceatmosphere energy fluxes have been illustrated in general terms. However, the contribution of leads to the turbulentenergy flux into the boundary layer and, more importantly, to heat and moisture transfer into the troposhere above the Arctic inversion requires more specific analysis. Such an analysis is currently in progress.

\section{CONCLUSIONS}

New sources of data on leads in Arctic sea ice and on surface-melt phenomena are provided by satellite and airborne remote sensing. The orientations of major leads in the Beaufort Sea mapped from visible-band satellite images are shown to be broadly correlated with geostrophic wind direction and have similar synoptic scale patterns. Preliminary results of airborne $1.06 \mu \mathrm{m}$ lidar transects over Baffin Bay demonstrate its great potential for highresolution mapping of open-water areas and, in winter/spring, for identifying their ice-crystal plumes. Some of these sub-visible plumes are observed to penetrate the Arctic inversion. Snow-melt maps for the entire Arctic, prepared for four summer seasons, have been used to derive surface-albedo data. The possible contributions of such data sets to verification and improvement of numerical sea-ice models are discussed. In addition, both the albedo and the lead data will enable assessments of the surface-energy balance over ice to be significantly extended in spatial and temporal contexts. For example, the variability of the surface-energy balance for the central Arctic attributable to variations in timing of snow melt on the ice is estimated to be equivalent to $0.66 \mathrm{~m}$ of ice melt.

\section{ACKNOWLEDGEMENTS}

This work was supported by the U.S. Office of Naval Research under a University Research Initiative Program 
contract N00014-86-K-0695. We thank M. Neary for drafting and $M$. Strauch for word processing. DMSP images are archived at the National Snow and Ice Data Center, University of Colorado.

\section{REFERENCES}

Andreas, E., C.A. Paulson, R.M. Williams, R.W. Lindsay, and J.A. Businger. 1979. The turbulent heat flux from Arctic leads. Boundary-Layer Meteorol., 17, 57-91.

Barry, R.G. 1986. The sea ice data base. In Untersteiner, N., ed. The geophysics of sea ice. New York, Plenum Press, 1099-1134. (NATO ASI Ser., Ser. B, Physics, 146.)

Batschelet, J. 1981. Circular statistics in biology. London, Academic Press.

Bourke, R.H. and R.P. Garrett. 1987. Sea ice thickness distribution in the Arctic Ocean. Cold Reg. Sci. Technol., 13(3), 259-280.

Colony, R. and E.A. Muñoz. 1985. Arctic Ocean Buoy Program data report: 1 January 1983-31 December 1983. Seattle, University of Washington. Polar Science Center.

Curray, J.R. 1956. The analysis of two-dimensional orientation data. J. Geol., 64, 117-131.

Hibler, W.D., III. 1985. Sea ice models and remote sensing. In Conference on Use of Satellite Data in Climate Models. Proceedings. Paris, European Space Agency, 87-94. (ESA SP-244.)

Klink, K. Unpublished. Space-time analysis of the surface wind field using vector-based principal components analysis. (Master's thesis, University of Delaware, 1986.)

Klink, K. and C. Wilmott. 1985. Comments on "Evaluating the similarity of geographic flows". Prof. Geogr., 37, 56-58.

McLaren, A.S. 1987. The under-ice thickness distribution of the Arctic Basin as recorded in 1958 and 1970: a comparison. In POAC 87; the 9th International Conference on Port and Ocean Engineering under Arctic Conditions, Fairbanks, Alaska. Proceedings.

McLaren, A.S., M.C. Serreze, and R.G. Barry. 1987. Seasonal variations of sea ice motion in the Canada Basin and their implications. Geophys. Res. Lett., 14(11), $1123-1126$

Marshunova, M.S. 1966. Principal characteristics of the radiation balance of the underlying surface and of the atmosphere in the Arctic. In Fletcher, J.O., B. Keller, and M. Olenicoff, eds. Soviet data on the Arctic heat budget and its climatic influence. Santa Monica, CA, Rand Corporation, 51-131. (Memo. RM-5003-PR.)

Maslanik, J.A. and R.G. Barry. 1989. Short-term interactions between atmospheric synoptic conditions and sea ice behavior in the Arctic. Ann. Glaciol., 12, 113-117.

Maykut, G.A. 1986. The surface heat and mass balance. In Untersteiner, N., ed. The geophysics of sea ice. New York, Plenum Press, 395-463. (NATO ASI Ser., Ser. B, Physics, 146.)

Mellor, M. 1986. Mechanical behavior of sea ice. In Untersteiner, N., ed. The geophysics of sea ice. New York, Plenum Press, 165-281. (NATO ASI Ser., Ser. B, Physics, 146.)

Morley, B.M. 1987. Alpha-2 observations of Arctic haze during AGASP-2. Menlo Park, CA, SRI International. (Final Rep. NOAA Contract 50, RANR 600043.)

Robinson, D.A., G.J. Kukla, and M.C. Serreze. 1985. Arctic cloud cover during the summers of 1977-1979. Palisades, NY, Columbia University. Lamont-Doherty Geological Observatory. (Tech. Rep. LDGO-835.)

Ross, B. and J.E. Walsh. 1987. A comparison of simulated and observed fluctuations in summer-time Arctic surface albedo. J. Geophys. Res., 92(C12), 13115-13125.

Scharfen, G., R.G. Barry, D.A. Robinson, G. Kukla, and M.C. Serreze. 1987. Large-scale patterns of snow melt on Arctic sea ice mapped from meteorological satellite imagery. Ann. Glaciol., 9, 200-205.

Steffen, K. 1987. Fractures in Arctic winter pack ice (North Water, northern Baffin Bay). Ann. Glaciol., 9, 211-214.

Thorndike, A.S. and R. Colony. 1980. Arctic Ocean Buoy Program data report: 19 January 1979-31 December 1979. Seattle, University of Washington. Polar Science Center.

Thorndike, A.S. and R. Colony. 1982. Sea ice motion in response to geostrophic winds. J. Geophys. Res., 87(C8), $5845-5852$.

Wadhams, P. and R.J. Horne. 1980. An analysis of ice profiles obtained by submarine sonar in the Beaufort Sea. J. Glaciol., 25(93), 401-424.

World Climate Research Programme. 1987. Report of the Second Session of the Working Group on Sea Ice and Climate. Geneva, World Meteorological Organization. (World Climate Programme 128.) 